\title{
RECUPERAÇÃO DOS CRÉDITOS FAZENDÁRIOS: MÉTODOS ALTERNATIVOS DE SOLUÇÃO AS CONTROVÉRSIAS TRIBUTÁRIAS
}

\section{RECOVERY OF FEDERAL CREDIT: ALTERNATIVE METHODSOF SOLUTION FOR THE TAX CONTROVERSIES}

Patrícia Silva Almeida

Mestranda em Direito pela Universidade de Marília - UNIMAR. Especialista em Direito Público pela Escola da Magistratura Federal do Rio Grande do Sul - ESMAFE/RS. Oficiala Registradora e Tabeliã de Notas do Município de Santa Salete, Estado de São Paulo. E-mail: jpalmeida@via-rs.com.br

Jonathan Barros Vita

Doutor e Mestre em Direito pela Pontifícia Universidade Católica de São Paulo - PUCSP. Mestre em Segundo Nível em Direito Tributário de Empresa pela Universitá Commercialle Luigi Bocconi - Milão (Itália). Especialista em Direito Tributário pelo Instituto Brasileiro de Estudos Tributários - IBET. Coordenador e Professor Titular do Programa de Doutorado e Mestrado em Direito da Universidade de Marília - UNIMAR. Advogado. Consultor Jurídico. Contador. E-mail: jbvita@gmail.com

Recebido em: 13/08/2017

Aprovado em: 15/12/2017

RESUMO: O presente ensaio visa apresentar alguns métodos alternativos de solução as controvérsias tributárias em virtude da dificultosa, e muitas vezes inexitosa, recuperação de créditos em fase de execução fiscal. Para tanto, apresenta por metodologia de trabalho o método hipotético-dedutivo, partindo de uma pesquisa essencialmente bibliográfica. Inicia-se com a descrição do processo de execução fiscal e as deficiências apontadas na recuperação dos créditos fiscais, seguido da análise dos dados apresentados pelo Instituto de Pesquisa Econômica Aplicada - IPEA, acerca do custo e do tempo médio das execuções fiscais federais no Brasil, culminando na apresentação de alguns métodos alternativos a solução de controvérsias tributárias vinculantes, a citar, o uso doprotesto extrajudicial das Certidões de Dívida Ativa, a transação e a arbitragem tributária,dispondo, ainda, de sugestivasmelhorias nos processos técnico-administrativos de execução dos referidos créditos.

Palavras-chaves:Arbitragem tributária. Execução Fiscal.Métodos Alternativos de Solução de Controvérsia Tributária.Protesto extrajudicial.Transaçãotributária.

ABSTRACT: The present essay aims to present some alternative methods of solution for the tax controversies due to the tough, and usually unsuccessful, recovery of credit in the tax execution. Therefore, it presents the hypothetical deductive method as methodology of work, starting from an essentially bibliographic research. It begins with the description of the tax execution procedure and the deficiencies pointed up in the recovery of tax credits, followed by the analysis of the data presented by the Institute for Applied Economic Research - IPEA, concerning the cost and average time taken by the federal tax executions in Brazil, culminating in the presentation of some alternative methods for the solution of binding tax controversies, such as the use of out-of- 
court protest of the Overdue Federal Liabilities Certificate, the transaction and the tax arbitration, and also propose an improvement in the technical administrative execution procedures of the quoted credits.

Key-words: Tax arbitration. Tax Execution.Alternative Methods of Solution for Tax Controversy.Out-of-Court Protest. TaxTransaction.

SUMÁRIO: Considerações Iniciais. 3 A execução fiscal nos moldes atuais: apontamentos sobre um sistema deficitário de cobrança. 2 A problemática questão do custo e do tempo das execuções fiscais no Brasil: apontamentos sobre a pesquisa do Instituto de Pesquisas Econômicas Aplicadas - IPEA. 3 Métodos alternativos de solução de controvérsias tributárias. 3.1 O Protesto Extrajudicial dos Créditos Tributários. 3.2 A transação tributária. 3.3 A arbitragem tributária. 4.4 Melhorias na qualidade da gestão administrativa dos créditos junto ao poder executivo fiscal.Considerações Finais. Referências Bibliográficas.

\section{CONSIDERAÇÕES INICIAIS}

Muito embora seja tratado o processo de execução fiscal judicial o principal meio de cobrança dos créditos fiscais da Fazenda Pública,o instituto em questão, de longa data, apresentase em crise,ocasionando ineficiência na recuperação dos créditos fazendários.

Ao realizarmos uma análise setorial acerca do volume das causas judiciais que ingressam ou que estão em andamento, verifica-se que em sua maioria pertencem ao contencioso tributário, representativo do volume das demandas postas junto ao Poder Judiciário, no geral improdutivas e com resultados insatisfatórios ao final.

Desse modo percebe-se a ineficiência na cobrança de dívidas, ocorrem por diversos fatores: a constante mudança nas normatizações tributárias; o excessivo tempo entre o vencimento da obrigação e a efetiva cobrança; a baixa qualidade do bem penhorado, a ausência de garantias, a ineficiência de sanções pelo descumprimento da obrigação, bem como a falta de informação sobre o patrimônio do devedor e a desnecessária repetição de procedimentos nas esferas administrativa e judicial, servem de incentivo ao aumento das controvérsias tributárias, elevando a discussão junto ao judiciário.

Aliado a esses fatores acima descritos, a morosidade do sistema executório,por ser o modelo executório brasileiro essencialmente judicial, tem agravado, em muito, a situação das execuções fiscais e os recentes procedimentos desjudicializadores parecem contribuir para uma cobrança mais célere, ao se atribuir aos atos executivos aos órgãos extrajudiciais, percorrendo um caminho mais ágil a recuperação do crédito tributário.

Em virtude de toda problemática exposta, aescolha pelo tema,objeto do presente artigo, vem apresentar meios alternativos à solução de controvérsias de natureza tributária, com ênfase no protesto extrajudicial de Certidões de Dívida Ativa, na transação tributária e na proposta de arbitragem tributária, medidas céleres e econômicas a fim de atenuar as dificuldades encontradas na recuperação dos créditos de natureza fiscal, já em fase de contencioso executório.

Ao acompanharmos as discussões fomentadas pelos dados de pesquisa descritos no Comunicado $\mathrm{n}^{\mathrm{o}}$ 127, de 04 de janeiro de 2012, do Instituto de Pesquisa Econômica Aplicada IPEA, abordando o custo e o tempo de espera dos processos judicializados promovidos pela Fazenda Pública Nacional e sua efetividade na recuperação dos créditos públicos, projeto de pesquisa desenvolvido no período de novembro de 2009 a dezembro de 2011, destaca a preocupação em solucionar os problemas inerentes ao executivo fiscal federal, vislumbrando as falhas até então encontradas. 
O desenvolvimento do artigo se dará primordialmente no âmbito do direito fiscal onde se buscará analisar o processo executivo fiscal na atualidade, casadoa legislação pertinente à temática, ${ }^{1}$ assim comovisa relacionar as possíveis soluções ao problema na pesquisa.

Destarte, objetiva-se com esse ensaio, apontar caminhos que levem à construção de uma nova forma de pensaro sistema público de recuperação dos créditos fiscais, sugerindoa utilização de mecanismos extrajudiciais, como protesto notarial,uma prática econômicaque venha a servir de estímulo a redução do investimento público aplicados aos atos de execução.

Para tanto, didaticamente, o presente trabalhoserá divido em trêstópicos: o primeiro" $A$ execução fiscal nos moldes atuais: apontamento de um sistema deficitário de cobrança" descreve os pontuais problemas enfrentados pelos operadores jurídicos no desenvolvimento regular do processo executivo fiscal nos moldes atuais; o segundo "A problemática questão do custo e do tempo das execuções fiscais no Brasil: apontamentos sobre a pesquisa do Instituto de Pesquisas Econômicas Aplicadas - IPEA"aponta-se representativadas afirmações constantes sobre o custo e o tempo do processo fiscal ao erário e, por fim; "Métodos Alternativos de solução de Controvérsias Tributárias Vinculantes", destacando a apresentação de alguns procedimentosdesjudicializadores, viáveis e de baixo custo,a solucionar à problemática posta em destaque, a saber: o protesto extrajudicial, a transação tributária, a arbitragem tributária e sugestivas melhorias na qualidade da gestão administrativa do poder executivo fiscal.

Como metodologia geral, optou-se pelo método hipotético-dedutivo, e quanto ao procedimento técnico, trata-se de um apanhado essencialmente analítico-documental, realizado com base nos dados de pesquisalançados no Comunicado do Instituto de Pesquisa Econômica Aplicada, bem como o uso de dados bibliográficos sobre o tema.

Por fim, a questão que se propõe a discutir ao logo do trabalho é: diante do cenário brasileiro dos problemas enfrentado pelo executivo fiscal, tido por moroso e ineficiente no trato a recuperação dos créditos públicos, é possível a adoção de métodos alternativos menos dispendiosos, como o protesto extrajudicial das Certidões de Dívidas Ativas, a transação tributária e a arbitragem tributária, a solução de controvérsias tributárias?

\section{A EXECUÇÃO FISCAL NOS MOLDES ATUAIS: APONTAMENTOS SOBRE UM SISTEMA DEFICITÁRIO DE COBRANÇA}

O modelode processo utilizado na execução fiscal no Brasil demonstra certa ineficiênciaà recuperação dos créditos postos a execução,quer seja pela morosidade no andamento processual, quer seja pelodispendioso investimento público nas tentativas de recuperação dos referidos ativos.

Considerada falaciosa a isonomia entre os sujeitos nos processos judiciais de natureza fiscal,em razão das vantagens que a legislação fiscal institui em prol da Fazenda Pública,apesar de todos os privilégios postos, ainda assim, o processo carece de efetividade.

Pelo fato do poder executivo emitir um título executivo próprio esimplificado (CDA),configura-se importante vantagem em relação ao sujeito passivo, sem maiores demonstrações de cálculos, o quedifere dos demais títulos executivos civis.

Por certo, a formação da certidão de dívida ativa é representativa de uma obrigação líquida, certa e exigível, créditos esses inscritos na forma da lei.

A propósito, com a inscrição, descreve Ricardo Lobo Torres (2005), o crédito que era simplesmente exigível, passa a ser exequível,demonstrandouma diferença significativa quanto a sua constituição.

Então, a certidão é a representação cabal de um título de natureza formal - o poder público formaliza unilateralmente seu título de crédito -, caracteriza-se por apresentar seus

\footnotetext{
${ }^{1}$ Referência a Lei Federal no 6.830, de 22 de setembro de 1980, Lei de Execução Fiscal, também conhecida apenas por LEF.
} 
elementos descritos de modo preciso: além do principal, a atualização monetária, os juros, a multa de mora e demais encargos.

Ademais, não se inicia uma execução fiscal com a menção genérica do débito, sem que seja descrita, na integralidade, o fato constitutivo da obrigação - tributária ou não -, sendo nula de pleno direito, a certidão de dívida ativa que obstar a possibilidade de defesa técnica. (CUNHA, 2016)

Mas essa não é apenas a única vantagem a ser observada.

Igualmente, se na formalização do título houver a ocorrência de alguma impropriedade em sua constituição, pode a Fazenda Pública substituí-la no decorrer do curso da execução fiscal, desde que venha a respeitar a inexistência do transito em julgado dos embargos à execução propostos.

Da mesma forma, percebe-se o processo de execução fiscal não está submisso ao juízo da recuperação judicial ou falência, embora configure no rosto dos autos do processo falencial, significando que o crédito público é indisponível ao concurso de credores.

Até o presente momento, com base no princípio da responsabilidade patrimonial, no ato de constrição de bens do devedor - por exceção apenas aos bens de natureza impenhoráveis --, ao executado carece a possibilidade de alegar atos de restrições pactuadas de modo convencional.

Urge observar, em virtude da autoridade que a Fazenda Pública exerce em razão do princípio da Supremacia do Interesse Público, na ocorrência de penhora de bens para fins de garantia de crédito, os bens constritos ficam indisponíveis automaticamente, em observância ao artigo 55, da Lei Federal ${ }^{\circ}$ 8.212/91.

Contudo, antes da procedência da averbação premonitória da execução junto aos órgãos públicos, ad exemplu, junto ao DETRAN e ao Registro de Imóveis, seus efeitos são idênticos ao de uma penhora antecipada.

Contudo, embora exista essa possibilidade de penhora antecipada, segundo dispõe Gustavo Caldas Guimarães de Campos (2009), a ineficiência na cobrança da dívida ativa ocorre em virtude da baixa qualidade do bem penhorado, a ausência total de garantias ou até mesmo a falta de informação confiável sobre o patrimônio do devedor.

No que se refere à substituição de bens ofertados garantidores da execução, a critério do poder público pode o executado, a qualquer momento, ser instado a realizar a troca do bem, ao passo que,o mesmo benefícionão é disponível ao devedor, fazendo apenaspassar pelo crivo fazendário.

Além do mais, à Fazenda Pública é cediço o uso de medidas antecipatórias de crédito redirecionando a ação executiva aos corresponsáveis, em razão de possíveis elementos configuradores de desvio de personalidade jurídica ou abuso de poder, bem como ao alcance de grupos econômicos que respondem solidariamente pelo débito de natureza funcional, nos termos do artigo 30, IX, da Lei Federal nº 8.212/91.

Não obstante ter a considerar todas as prerrogativas processuais fornecidas ao credor público no âmbito judicial é fato, conforme aponta Tiago Scherer (2005), existem argumentos tendenciosos, originários do Poder Executivo, justificando a transformação da execução físcal em modelo de via expropriatória administrativa.

Percebe-se de todo feito, embora existam esforços para tornar a execução mais eficaz, inegável são as dificuldades enfrentadas pelo poder judiciário em razão do crescente volume de execuções fiscais sem conclusão, pelas frustradas tentativas de encontrar o próprio devedor ou,pela não localização de bens penhoráveis e, ainda, pelas ocorrências de desconstituições irregulares das empresas e insolvências civis, entre outros fatores.

Do mesmo modo, tem-se observado na prática,que as Fazendas Públicas não promovem execuções fiscais de pequena monta, fixando em cada esfera os limites à dispensa de sua 
inscrição em dívida pública (o correspondente a $\mathrm{R} \$ 1.000,00$ ), assim como, inscrito, porém não executados, os créditos de até $20.000,00$ no âmbito federal. ${ }^{2}$

Tal circunstância releva que a dispensa das execuções de valores menores,representam uma considerável perda do investimento público àbusca dosativos fazendários.

Segundo defende o ex-Corregedor Geral de Justiça do Tribunal de Justiça do Estado de São Paulo,Desembargador José Renato Nalini, sensibilizado pela crise do processo de execução fiscal, retrata o desempenho de uma função anômala exercida pelo Poder Judiciário. Não se está a aventar que oPoder Judiciário esteja se eximindo de exercera atividade de julgar, pois a este cabe resolver conflito em virtude do firmado princípio constitucional da inafastabilidade da jurisdição; e explicita com propriedade:

Todos os anos o Governo, suas Autarquias e Fundações - aí compreendidas União, Estados e Municípios - arremessam à Justiça milhões de CDAs Certidões de Dívida Ativa, que darão origem a execuções físcais. O Judiciário se conforma com a situação esdrúxula. Aceita ser cobrador de dívida. Mesmo sabendo que não tem estrutura, pessoal nem gestão eficiente para fazer funcionar um setor nevrálgico. Todos têm interesse em que os devedores recolham ao Erário o devido. Se eles se recusarem a pagar, o ônus de sustentar a máquina sempre perdulária e quase sempre ineficiente - recairá sobre os demais.(NALINI, 2005, p.1)

Como visto o congestionamento nas varas destinadas a atender a Fazenda Pública em juízo, em face da ausência de infraestrutura (recursos humanos e materiais)dificultam o atendimento da demanda, sendo apenas mais um dos problemas enfrentados à satisfação do crédito público.

O deslocamento da cobrança ao poder judiciário, em uma tentativa desesperadora de alcançar os bens do executado, não transforma, segundo Tiago Scherer (2005, p. 4), "o judiciário em uma repartição fazendária e seus servidores e juízes em agentes fiscalizadores”.

E não obstante o uso exacerbado dos meios de defesa técnica usados pelos devedores firmados em termos legais, casada à permissiva legislação tributária no que tange aos institutos da prescrição fiscal, são também entraves relevantes ao sistema creditório como um todo.

Destarte, para além de diversos outros motivos que podem ser elencados, é certo o prejuízo amargado a todos os contribuintes e ao Poder Judiciário, em razão dos reveses que a execução fiscal enfrenta.

Para tanto, a fim de comprovação das alegações postas acima, passamos a discorrer, na sequência, a análise dos dados levantados pelo Instituto de Pesquisa Econômica Aplicada acerca da realidade das execuções fiscais no âmbito federal.

\section{A PROBlemÁtica QUESTÃo do CUSTO E DO TEMPO DAS EXECUÇÕES FISCAIS NO BRASIL: APONTAMENTOS SOBRE A PESQUISA DO INSTITUTO DE PESQUISAS ECONÔMICAS APLICADAS - IPEA}

O Conselho Nacional de Justiça com o intuito de aperfeiçoar o processo de cobrança da dívida ativa federal, firmou parceria com o Instituto de Pesquisa Econômica Aplicada - IPEA, visandomensurar aquestão das execuções fiscais federais, através de umprojeto de pesquisa o qual dimensionouo efetivo custo e tempo de tramitação de um processo executivo fiscal da União junto à Justiça Federal.

\footnotetext{
${ }^{2}$ Segue o disposto na Portaria no 75 , de 22 de março de 2012, do Ministério da Fazenda, com alterações subsequentes pela Portaria n 130 , de 19 de abril de 2012, também do Ministério da Fazenda.
}

Revista de Direito Brasileira | São Paulo, SP | v. 19 | n. 8 | p. 107 - 121 |Jan./Abr. 2018 
Os dados gerados produziram informações significativas ao alcançar o "estado da arte" dos processos executivos fiscais federais, assim como objetivou medir o desempenho da Procuradoria Geral da Fazenda Pública Nacional - PGFN -, no período compreendido entre os anos de 2009 a 2011.

As informações reproduzidas no corpo deste trabalho, é fiel ao Comunicado $n^{\circ} 127$, de 4 de janeiro de 2012, divulgado e publicado pelo supramencionado Instituto de Pesquisa.

A pesquisa partiu do denominado Processo de Execução Fiscal Médio (PEFM), representativo da média dos processos de execução fiscal que tiveram sua baixa definitiva junto a Justiça Federal.

A conclusão apontou como resultado, um tempo médio de tramitação processual de 3.571 dias, ou seja, nove anos, nove meses e dezesseis dias, com uma baixa probabilidade de êxito (em torno de $25,8 \%$ ).

Percebe-se, ainda que, o objeto de execução fiscal, em sua maioria, é fruto de dívidas relacionadas aos impostos federais $(52,1 \%)$, seguida das contribuições sociais federais $(37,5 \%)$ e, por residual, verbas de multas, aforamentos, laudêmios e outras obrigações $(9,9 \%)$.

No que se refereaos custos executórios, a pesquisa descreveu todas as etapas que compõem uma execução fiscal, comportando desde a elaboração da petição inicial, até a respectiva baixa definitiva do processo. Foi indicado, o valor gasto, em média, porunidade de execução fiscal o corresponde a R \$ 5.606,67.

Contudo, segundo o IPEA, o relatório conclusivo aponta como ponto de equilíbrio que justificaria a movimentação do aparato estatal a promover um executivo fiscal judicial, para valores a partir de $\mathrm{R} \$ 21.731,45$.

Tal constatação faz identificaruma base de justificação à fixação do piso mínimo aconcretaabertura de execuçãonos moldes atuais (aproximadamente $\mathrm{R} \$ 20.000,00$ ), pois, o próprio IPEA em sua conclusãoapontou antieconômico movimentar um processo executivo fiscal inferior ao valor referenciado na pesquisa.

Neste contexto, nos termos observados, conclui-se que não basta a adoção de um novo piso mínimo para se promover a execução fiscal, mister se faz implementar medidas eficazes de adoção de redução do denominado risco moral (moral hazard) associado ao não pagamento do tributo, conforme afirma:

[...] é importante que a divulgação do novo valor dê-se no contexto de simultânea publicação de uma clara política de recuperação dos créditos fiscais inferiores a $\mathrm{R} \$ 20.000,00$, sob pena de sinalizar à sociedade a desimportância do correto recolhimento de impostos e contribuições. (IPEA, 2012, p. 15)

E para efeito dessas constatações, o Ministério da Fazenda editou a Portaria MF $\mathrm{n}^{\mathrm{o}} \mathbf{7 5}$, de 26 de março de 2012, a qual expede algumas instruções para autorizar a adoção de formas extrajudiciais, envolvendo débitos de qualquer monta, inscritos, ou não, em dívida pública.

Então, frente a todo o exposto, a seguir, elencamos algumas possíveis alternativas de natureza extrajudicial,para o resgate dos créditos públicos, consideradas de baixo custo ao poder público.

\section{MÉTODOS ALTERNATIVOS DE SOLUÇÃO DE CONTROVÉRSIAS TRIBUTÁRIAS}

Verifica-se, com base na análise das informações resultantes da pesquisa retro mencionada, mister se faz reavaliar a formulação do executivo fiscal, prezando pelamáxima efetivação e disponibilizando formas alternativas de solução às demandas com baixo custo ao erário. 
Sabendo que o futuro da execução fiscal depende de medidas desjudicializadoras eotimizadoras de valoração ao processo contencioso administrativo tributário, ${ }^{3}$ nessa acepção, figuram-se algumas propostas alternativas complementares àsolução daquestão creditória fiscal.

\subsection{O Protesto Extrajudicial dos Créditos Tributários}

Em paralelo a pesquisa desenvolvida pelo IPEA, foi gestada a Lei Federal $n^{\circ} 12.767$, de 27 de dezembro de 2012, a qual por intermédio de seu artigo 25 vem incluir o parágrafo único, ao artigo $1^{\circ}$, da Lei Federal $n^{\circ}$ 9.492, de 10 de setembro de 1997, autorizandoo protesto das certidões de dívida ativa. ${ }^{4}$

Todavia, uma parte da doutrina, como leciona José Carlos Alves (2016), onde entende que o artigo 25, da Lei Federal $n^{\circ}$ 12.767/2012, nada mais fez do que reafirma uma situação preexistente, dado que sempre foi sustentada a viabilidade do protesto de CDA's como um título de crédito já firmado expressamente no Código de Processo Civil Brasileiro, ínsito no caput do artigo $1^{\circ}$, da Lei de Protesto, contido na expressão "outros documentos de dívida", por assim não constar do rolnumerusclaususde títulos cambiais, ampliando os documentos passíveis ao protesto.

Historicamente, o protesto surgiu ligadoexclusivamente aos títulos de créditos de natureza cambiária e representava apenas um meio de prova do descumprimento das obrigações disposta nas cártulas (SANTOS, 2012).

Com o passar do tempo, entendeu-se, graças aos resultados positivos de efetividade na recuperação dos créditos privados, a extensão do instrumento em proveito de algumas situaçõesde natureza pública que prezam a celeridade, a efetividade, a segurança jurídica e a economia processual, a citar, os casos em que se protestam sentenças de alimentos, documentos eletrônicos de dívida,sentenças de obrigações líquidas e certas, entre outras formas permissivas a saída da esfera executória judicial ao âmbito extrajudicial de cobrança.

Mesmo por que, evidentemente, não há que se fazer distinção entre a tutela pública e a tutela privada, mormente,no que se refere aos direitos de recuperação de seus créditos.

Sob essa ótica, conforme destaca Emanoel Macabu Moraes (2014, p. 110), ao considerar os documentos de dívida, nos moldes da Lei de Protesto, iguais: "[...] não se podendo dar a Fazenda Pública menos do que se confere aos particulares."

Então, se o credor privado tem obtido êxito na utilização do instrumento do protesto, não há motivo para não incorporar ao Estado tal possibilidade de cobrança.

Além disso, a própria Lei de Execução Fiscal, nos termos do artigo 36, descreve que cabe a Fazenda Pública normatizar a cobrança da dívida ativa, inclusive de forma extrajudicial.

Portanto,resta por evidente, o dever de o administrador público procurar regatar aos cofres públicos os créditos que são próprios, ${ }^{5}$ desde que seja realizada através dos meios que a legislação tributária lhe confere.

E neste sentido,é possível a busca de um modo eficiente à Fazenda Pública e menos gravoso ao devedor, segundo o juízo discricionário do administrador público.

Pois bem, corroborando a esse entendimento, existe o posicionamento favorável do Tribunal de Contas do Estado de São Paulo, recomendando o protesto das CDA's como ferramenta a coibir a inadimplência perante o FISCOeaperfeiçoar a cobrança dos créditos

\footnotetext{
${ }^{3}$ Menção a Lei Federal n ${ }^{\circ}$ 9.871, de 29 de janeiro de 1999, regula o processo administrativo fiscal no âmbito federal.

${ }^{4} \mathrm{O}$ dispositivo prevê expressamente: "Incluem-se entre os títulos sujeitos a protesto as certidões de dívida ativa da União, dos Estados, do Distrito Federal, dos Municípios e das respectivas autarquias e fundações públicas”.

${ }^{5}$ Chamamos atenção a Lei de Responsabilidade Fiscal (Lei Complementar $n^{\circ}$ 101/2000), ao instituir no seu artigo 11 requisitos a serem considerados nos atos de governança, pois não se pode deixar de realizar a arrecadação dos créditos públicos enquanto gestor do erário público.
}

Revista de Direito Brasileira | São Paulo, SP | v. 19 | n. 8 | p. 107 - 121 |Jan./Abr. 2018 
públicos, reforçando que esta ideia é um instrumento menos gravoso aos devedores, tendo em vista a inexistência de penhora de bens. ${ }^{6}$

A ineficácia arrecadatória do mecanismo de protesto é baixa em comparação ao processo judicial.

E sobre tal afirmação, a experiência obtida pelo Instituto Nacional de Metrologia, Normalização e Qualidade Industrial - INMETRO, no Estado do Rio Grande do Sul, acerca do êxito nas cobranças de seus créditos via instrumento de protesto, ${ }^{7}$ relata ser o índice de recuperação consideravelmente alto e que desde 2009, oportunidade em que foi aprovado um parecer sobre o tema, concluso: "[...] é melhor ter um meio eficiente de cobrança dos pequenos créditos do que abarrotar o Judiciário com milhares de execuções fiscais", conforme situa o Coordenador-Geral de Cobrança e Recuperação de Créditos da PGF, Albert Caravaca (BRAGA, 2009, p. 1).

Contudo, temos a considerar os argumentos contrários.

$\mathrm{Na}$ esteira do pensamento de Emanoel Macabu Moraes (2014), os argumentos que têm lastros na inadimplência contra o poder público apresenta por suporte a certeza da prescrição ${ }^{8}$ intercorrente (artigo 40, da Lei de Execução Fiscal), na expectativa de ocorrer anistias fiscais, parcelamentos, ${ }^{9}$ ainda que se tenha a plena certeza da ineficiência dos resultados para o credor público,dos mecanismos postos em favor do devedor.

É importante acrescentar que perante o Supremo Tribunal Federal, houve a tentativa de obstar o uso do instrumento de protesto, através da ADI n ${ }^{\circ} 5.135 / \mathrm{DF},{ }^{10}$ alegando a Confederação Nacional da Indústria (CNI), que a matéria relativa ao protesto extrajudicial seria, pois, estranha ao tema central da Medida Provisória que deu origem a Lei Federal $n^{\circ} 12.767 / 2012$, devendo as emendas guardar afinidade com a proposição original da medida provisória.

Nos argumentos trazidos pela postulante,se afirmouexistir uma inconstitucionalidade material, vez que a CDA é um título executivo e, per si o uso do protesto extrajudicial seria coerção indireta sobre o devedor, afrontando dispositivos constitucionais (art. 5, XIII e XXXV, art. 170, inciso III e o art. 174, da Constituição Federal).

Todavia, o resultado da ação, nos termos do julgado pelo Plenário do Supremo Tribunal Federal, restou improcedente, interpretando, por maioria dos votos, que a utilização do protesto pela Fazenda Pública para promover a cobrança extrajudicial de CDA's visa acelerar a recuperação dos créditos tributários sendo, portanto, constitucional e legítima.

Além do mais, no que se cinge aos custos e ao tempo gasto com o protesto, lembramosa remessa a protesto e retorno de informações (via convênio), na maioria dos casos, se dão por intermédio de arquivos eletrônicos, representando um procedimento célere, seguro e econômico ao credor público.

Inclusive, nos termos da Portaria n ${ }^{\circ}$ 396/2016, da Procuradoria da Fazenda Nacional, nos termos do artigo 10, reafirma-se a possibilidade de protesto extrajudicial das Certidões de Dívida Ativa federais, comportando um dos procedimentos de inclusão do devedor no Regime

${ }^{6}$ Referência ao julgado: TCE/SP. Tribunal Pleno. TC no 041852/026/10, Relator Conselheiro Alexandre Manir Figueiredo Sarquis, julgado em 08/02/2012.

7 O êxito é significativo. A diferença efetiva entre a execução fiscal e o protesto. Com um prazo de recebimento de três dias úteis contra o aproximado dez anos de execução judicial, faz reconsiderar o custo aos cofres públicos como baixo.

${ }^{8}$ Importante frisar, o protesto da CDA não tem o condão de interromper a prescrição, não se aplicando o disposto no artigo 202, III, do Código Civil brasileiro, visto que em matéria tributária, exige-se nos termos constitucionais, a edição de Lei complementar, no caso previsão no Código Tributário Nacional.

${ }^{9}$ Menção específica à perda de receitas com os parcelamentos concedidos pela União (REFIS), uma perda representativa de 18,6 bilhões por ano para a União, segundo afirma Jorge Rachid, secretário da Receita Federal do Brasil, em notícia divulgada recentemente pelo Jornal Estado de São Paulo.

${ }^{10}$ BRASIL. STF. ADI no 5.135/DF. Tribunal Pleno. Rel. Min. Luiz Roberto Barroso. Julgado em 09/11/2016. DJe 11/11/2016. 
Diferenciado de Cobrança de Crédito (RDCC), os quais a partir da inclusão neste regime são automaticamente direcionados ao protesto por falta de pagamento, desde que respeitado a suspensão de sua exigibilidade, ou se garantido integralmente, bem como ainda esteja com pedido de parcelamento deferido.

E, conforme expõe Fátima Pacheco Haidar (2016), a Portaria em questão visou aprimorar a cobrança dos créditos tributários efetivamente inscritos em dívida ativa, prestigiando o aclamado princípio da eficiência, ínsito na Constituição Federal, em seu artigo 37, uma tentativa de promover com eficiência e segurança o resgate dos haveres tributários.

Esse tipo de ação aponta a um procedimento de desjudicialização das demandas junto ao Poder Judiciário, alinhado ao pensamento a um moderno processo civil, que preza suas ações na possibilidade de autocomposição fora do ambiente judicial.

Em suma compreendemos que a apresentação das CDA's para protesto, em especial ao resgate dos créditos de qualquer valor (desde que siga à declaração do órgão público competente reconhecendo que a dívida foi regularmente inscrita e segue os requisitos legais), uma alternativa, em potencial, a ser aplicada.

\subsection{A transação tributária}

Existente previsão alguns Estados da Federação e previsto em Projeto de Lei Federal ${ }^{11}$, o instituto da transação tributária, encontra-se regulado no Código Civil Brasileiro, nos artigos 840 ao artigo 850, e representam a possibilidade de prevenir ou findar litígios mediante possíveis concessões mútuas pactuadas por ambas as partes.

Como percebe, o fenômeno é característico de uma autocomposição bilateral, com mútuas concessões, e como sustenta Priscila Faricelli de Mendonça (2013) para que exista uma transação, necessário se faz que haja a predisposição de solução de um conflito prévio entre as partes, o que não impede haver uma demanda judicial em curso, mas que se tenha o desejo de concluí-la da melhor forma possível.

Em que pese operar, precipuamente, em direitos patrimoniais indisponíveis, é recente no âmbito do direito público a sua aplicação, em face da mitigação a tradicional concepção de direito público, existe a possibilidade do poder público renunciar alguns valores quanto perfectibiliza o ato transacional. ${ }^{12}$

Quanto ao deparamos com projetos de recuperação de créditos tributários (REFIS e PAES, por exemplo) em razão desses parcelamentos, ocorre uma disposição parcial do crédito aceito como forma de transação tributária, desde que esteja lastreada pela legalidade estrita, ou seja, necessita de uma lei que autoriza a sua concessão, nos termos dos artigos 156, III e artigo 170, do Código Tributário Nacional.

Seguindo nesta esteira de entendimento, Fábio Artigas Grillo (2012) consigna que com o marco de uma autorização legislação específica, haverá a possibilidade de se cogitar o instituto da transação em matéria tributária, com requisitos e condições que concretizem a solução consensual.

Assevera Heleno TaveiraTorres (2008), com devido aporte legal, não há o porquê negar o uso transação tributária como forma de solução de controvérsias, uma vez que inexistem dispositivos legais na definição de tributos (artigo $3^{\circ}$, do CTN) que impeça o uso de tal método.

Ademais, é perfeitamente viável instigar o acordo entre o fisco e o contribuinte, pois na maioria dos casos,não constitui representativo de renúncia fiscal ao crédito, sendobenéfica ao erário, ao invés de levar anos discutindo créditos em demandas judiciais fadadas ao fracasso.

\footnotetext{
${ }^{11}$ Referência ao Projeto de Lei Federal no 5082/2009, acerca da transação tributária.

${ }^{12}$ Lembrando a necessária observância a Lei de Responsabilidade Fiscal, no que tange a configuração de renúncia de receitas.
} 
Argumentos contrários à tese da transação tributária, temos a citar Hugo de Brito Machado (2008) firmando que nem sempre haverá a extinção do crédito tributário, tendo em vista que ao se considerar a transação um novo prazo ou condição especial de pagamento de tributação ao contribuinte, nem sempre terá o condão de sua extinção.

A transação na verdade, busca extinção do litígio, contudo se não cumprida, não extingui a execução. Só o pagamento integral extingue o crédito efetivamente.

A transigibilidade do crédito tributário já é uma prática corrente entre os fiscos: federal, estaduais e municipais. Nestes termos, segundo Priscila Faricelli de Mendonça acerca do ato da transação forma alternativa de solucionar discussões tributárias processuais, sustentando:

[...] não só estimula o diálogo entre os sujeitos envolvidos na relação jurídicatributária, mas também permite que a tributação se dê de forma participativa, o que por certo confere segurança, confiabilidade e também reciprocidade nas relações tributárias, as quais são complexas e nada cordiais pela visão do contribuinte. Tudo, sempre, em respeito a legalidade e a tipicidade tributárias (art. 150, I, da Constituição Federal). (MENDONÇA, 2013, p. 190)

Enfim, a proposta é em linhas de seguir uma tendência de aproximação aautocomposição, com vistas a aproximar o poder fazendário e o contribuinte, numa tentativa de simplificar o desfecho das demandas fiscais, antes mesmo de desencadear o processo executório, propondo-se a ser ummeio participativo e célere a solucionar conflitos dessa natureza.

\subsection{A arbitragem tributária}

A arbitragem, conhecida como um meio heterocompositivo de solução de conflitos, é um importante mecanismo adjudicatório de base consensual, temos a considerar outro método viável e adequado a solucionar demandas de cunho tributário, em razão de apresentar duas vantagens: uma, por ser uma decisão imparcial proferida por um técnico adotado por escolha das partes (manifestação expressa) e, outra; por trazer benefícios por ser ágil todo o procedimento arbitral.

No entanto, a celeuma que se estabelece frente aos aspectos positivos do uso de tal método, se seria, ou não, possível de aplicação nas controvérsias tributárias. A possibilidade da arbitrabilidade na esfera pública surge para além da mera observância da capacidade das partes e do direito posto a disponibilidade (MENDONÇA, 2013).

Uma análise superficial coloca em dúvida a existência de óbice à indisponibilidade do crédito tributário por ser público e reverte a coletividade, se a fazenda pública pode ou não, eleger a arbitragem como meio alternativo, porque, o ente estatal deve buscar o meio judicial, à luz da estrita legalidade, firmando a existência de real vantagem na escolha deste meio.

O interesse público envolvido não absoluto indisponível, na medida em que a prevalência é o interesse em resolver os conflitos da sociedade, e o fato de ser público é em grande parte, representativo dos interesses individuais do estado. Indisponível é a competência tributária, não o crédito (TORRES, 2008).

Por divergente a prática da arbitragem no âmbito tributário, encontramos o posicionamento de Hugo de Brito Machado (2008) ao defender que o direito do fisco de arrecadar tributos é indisponível e, assim, impraticável aplicar tal método.

Contudo, ao discordar com tal posição, temos a afirmar que se o Código Tributário Nacional prevê a disponibilização de créditos através de alguns institutos como a anistia, a remissão, o parcelamento e a transação, desnecessário nos parece eleger a arbitragem como meio discricionário da administração fiscal que venha a afrontar a legalidade tributária.

Assim, existem dois requisitos essenciais, a disponibilidade e a patrimonial idade do crédito, como aduz Priscila Faricelli de Mendonça (2013) já está consolidado o uso da arbitragem 
pelo poder público, desde que esteja revestida de legalidade e a depender da anuência do contribuinte quanto a sua adoção.

E nestes termos, temos a mencionar o Parecer exarado pela da Advocacia Geral da União (Parecer AGU/SRG $n^{\circ}$ 1/2017), posicionando firme entendimento sobre a aplicação da arbitragem a solucionar controvérsia tributária no âmbito da Administração Pública Federal, em face da inexistência de vedação legal em sentido contrário. ${ }^{13}$

Então, nos parece que a instituição da arbitragem para fins de solucionar conflitos para sua efetividade, para além de preventiva de constituição de créditos, necessita de elaboração de lei material (complementar), dispondo sobre a aplicação da sentença arbitral para que se tenha o condão de extinguir o crédito já constituído, sob pena de burla ao artigo 146, da Constituição Federal.

Como visto, é teoricamente possível pensar na arbitragem aplicada ao direito tributário. O Grupo de Estudos em Arbitragem Tributária - CBAR (2017) trabalha para reafirmar tal possibilidade, alegando que sob o ponto de vista do Fisco, a regulamentação legislativa da arbitragem neste âmbito e seus efeitos (processual ou administrativo sancionatório) a tornarão um mecanismo de solução de controvérsia legítima, eficaz e bem sucedida no Brasil.

Em suma, o uso da arbitrabilidade das controvérsias tributárias, se respeitado os requisitos de legalidade estrita e de patrimonialidade, ao optar a Fazenda Pública pela solução mais econômica e com maior de êxito conclusivo, não se estará a renunciar o crédito tributário, mas sim resolvendo um conflito em respeito a autonomia das partes envolvidas no litígio e, por fim, nada impedindo a renuncia pela esfera judicial. ${ }^{14}$

\subsection{Melhorias na qualidade da gestão administrativa dos créditos junto ao do poder executivo fiscal}

Além da viabilidade do protesto extrajudicial, da transação e da arbitragem no âmbito tributário, temos a discutir outros modos de aperfeiçoamento no âmbito das atividades administrativas, mormente, apresentado como soluções de ordemadministrativa e técnica.

É indubitável o impacto negativo dos milhares de processos administrativos que se encontram parados, em virtude do excedente volume processual.

De acordo com o juiz federal Renato Lopes Becho (2004), a Receita Federal do Brasil levou vários anos (desde 2000 a 2014) para fins de concluir o programa de informática, necessário para o gerenciamento dos pagamentos efetuados junto ao programa de regularização tributária, popularmente chamado REFIS, iniciado desde 2000.

Isso representa, significativamente, a ausência de controle acerca do processamento dos créditos pagos ou em acordo de parcelamento, apontando um despreparo técnico sobre seus atos de governança.

Do mesma forma, de longa data, tem-se observado o descumprimento do contido no Decreto-Lei no 1.687/1979, o qual determina à Fazenda Nacional, no prazo de 90 dias para o encaminhamento do título à execução, e não demore quase cinco anos, como vem sendo efetivamente praticado.

\footnotetext{
${ }^{13} \mathrm{O}$ objeto da controvérsia tributária que originou o Parecer refere-se às contribuições previdenciárias sobre os pagamentos realizados aos profissionais autônomos que prestam serviços ao Programa de Assistência à saúde de servidores públicos do Banco Central do Brasil.

${ }^{14}$ Em que peseo amplo posicionamento a amplitude da arbitragem em qualquer demanda tributária, urge destacar, nossa posição com ressalvas, tendo em vista o critério de especificação da controvérsiatributária de grande vulto. Algumas demandas dispõem de elaboração de tese jurídica com um maior grau de reflexão, em virtude da repercussão junto ao erário, a citar o caso da tributação envolvendo o ISSincidente sobre as Sociedades Uniprofissionais (SUP), questionamento que envolve a incidência ou não de alíquota fixa sobre o serviço, com ênfase, segundo STF e STJ, no Regime Diferenciado de Tributação (RDT).
} 
Por tal razão, poderia ser gestado um sistema de aprimoramento inteligente da qualidade dos créditos executados, seguindo uma ordem de antiguidade, assim como poder monitorar dados do perfil do executado - grandes devedores contribuintes precisam de tratamento especializado, unificando as execuções e possibilitando acordos judiciais -, informações essas que poderiam surgir por intermédio por entrelaçamento de informações de outros órgãos públicos via convênios.

Outro fato importante, decisivamente, obter-se-ia maior êxito as reduções das execuções fiscais, se o FISCO reconhecesse de pronto, a prescrição intercorrente (PAULSEN, 2007).

A recente implantação do Regime Diferenciado de Cobrança de Créditos, fruto da Portaria PFN no 396/2016, sob a égide do princípio da eficiência, no seu artigo 20, reforça a determinação da suspensão (segundo o disposto no artigo 40, da Lei Federal $n^{\circ}$ 6.830/80), repisa os fundamentos de suspensão, cujo valor seja inferior a $\mathrm{R} \$ 1.000 .000,00$ (um milhão de reais), sem garantia hábil a satisfazer o crédito executado (integral ou parcial), também considerando as ofertadas sem lastro comercial ou de custosa alienação.

Nesse sentido, uma premissa básica que está em conformidade com nossa posição, segundo descreve Tiago Scherer $(2015$, p.15) caberia ao credor "[...] classificar a qualidade de seu crédito, para que não sobrecarregue o Judiciário com execuções físcais infrutíferas".

Mas vejamos, embora venha a ocorrer à mencionada suspensão das execuções, por problemas em encontrar bens executáveis ou de baixa liquidez, depreende-se que nos termos do artigo 22, da supramencionada Portaria n 396/2016, haverá um maior controle para se evitar a declaração da prescrição intercorrente.

Segundo Renato Lopes Becho (2004), a situação nas varas da Justiça Federal no município de São Paulo, retrata o extenso volume de processos parados, com chances de arrecadação dos créditos estimados a zero percentual, sendo, do universo das ações executivas que tramitam originários dos créditos públicos, cerca de $2 / 3$ do volume estão a esperar a declaração da prescrição.

E neste ponto, seria necessária uma atuação conjunta entre o poder executivo e o poder judiciário - força tarefa -, para baixar em torno de 200 mil processos federais, só na cidade de São Paulo, a espera da extinção.

Como sugestão, Renato Lopes Becho, anota:

A PFN poderia, também, passar a atender os advogados dos contribuintes. Assim, um canal direto de solução das controvérsias seria formado e, muitos casos, não precisariam da intermediação dos juízes. Hoje o advogado tem o direito de ser atendido pelo juiz, mas não pelo procurador da Fazenda Nacional. Esse órgão do Poder Executivo poderia aprimorar seus procedimentos. Eles fazem tudo o que podem para deixar o processo de execução fiscal ativo, ainda que a chance de êxito não mais exista. (BECHO, 2004, p. 1)

Convém pensar em um incentivo por parte do Conselho Nacional de Justiça estimulando a Fazenda Pública, a realização de providências realmente efetivas à cobrança, sem contrariar ou suprimir a participação do advogado público dentro do processo judicial.

Outrossim, interessante seria o convite ao Ministério Público para atuar como custus iuris, melhorando a fiscalização do cumprimento da lei nas execuções dessa natureza.

Como já mencionado outrora, a Receita Federal não tem cumprido o ajuizamento dos processos em tempo rápido, cabendo ao Parquet investigar quais os motivos da demora. Execuções fiscais propostas tardiamente contribuem negativamente ao resultado das demandas.

Agora, importante destacar, a existência de projetos com iniciativas estratégicas junto ao Instituto Innovare, primando pela celeridade, acesso e racionalização do uso do sistema judicial brasileiro. 
Um exemplo apresentado foi projeto titulado "Execução Fiscal Eficiente" desenvolvido pelo Tribunal de Justiça do Estado de Minas Gerais, no ano de 2015.

Basicamente, o projeto foi instituído, por intermédio de uma Portaria Conjunta $n^{\circ} 373$, de 10 de setembro de 2014, promovendo uma iniciativa a fim de redução do congestionamento das execuções fiscais dos entes municipais e estadual em Minas Gerais.

$\mathrm{O}$ intuito do projeto era garantir a agilidade e a qualidade nos trâmites processuais judiciais, incluindo por excelência a gestão operacional na fase administrativa.

O principal objetivo seria fomentar a comunicação e integração entre os Poderes e Instituições, desenvolvendo estratégias de redirecionamento do problema a outros meios menos onerosos como: o estimulo a conciliação extrajudicial (realizados por agentes imparciais, notariado), a disponibilização de informações as entidades de proteção ao crédito (SERASA, SPC, entre outras), bem como a possível securitização da dívida - uma espécie de operação de crédito para fins de antecipação de receitas.

Portanto, o bom desenvolvimento processual se faz através da criação de um amplo sistema de cooperação de recuperação dos créditos públicos, através de movimentos desjudicializadores, vêm trazendo novas perspectivas de atuação, unindo esforços entre os agentes envolvidos na relação tributária, para fins de alcançar os melhores resultados possíveis.

\section{CONSIDERAÇÕES FINAIS}

Por todo o exposto, procurando manter a coerência entre as premissas firmadas e o objeto da presente pesquisa, com a convicção de ter alcançado os objetivos inicialmente traçados, apresentamos as seguintes conclusões:

a) Constatada a existência de uma crise no processo de execução fiscalperante o Poder Judiciário, razão pela qual urge repensar o instituto como vem sendo apresentado nos moldes atuais;

b) Embora a Fazenda Pública disponha de prerrogativas e várias facilidades processuais, os resultados obtidos na recuperação dos créditos públicos originários desse falho modelo processual, é extremamente baixo se comparado ao gasto público direcionado ao seu resgate;

c) Em que pesem todos os esforços realizados pelo Poder Judiciário em desempenhar sua típica função de julgar, o panorama traçado a realidade posta às execuções fiscais,revelaque o Poder Judiciário tem exercido uma "função anômala", ou seja, vem exercitando uma atividade que não lhe é típica, inócua, atividade esta que pode ser desempenhada pela esfera administrativa;

d) As informações descritas através dos dados da pesquisa desenvolvida pelo Instituto de Pesquisa Econômica Aplicada - IPEA demonstrama realidade do custo e do tempo gastos em média pela Fazenda Pública Federal ao propor as execuções fiscais junto à justiça Federal. Se considerar o custo total dispendido na propositura da ação e a probabilidade de êxito, parte-se da premissa de que é economicamente inviável promover uma execução fiscal pela PGFN em valores inferiores a $R$ \$ 21.731,45; quando o tempo de espera é de aproximadamente uma década;

e) Dentre as formas alternativas de recuperação do crédito tributário, está o protesto da certidão de dívida ativa, um meio indireto e de baixo custo que serve a qualquer créditofiscal executável;

f) Outros procedimentos, como a arbitragem e a transação tributária, representam um avanço significativo na prevenção de litígios. Apesar das críticas doutrinárias, são meios possíveis de aplicação na fase executiva, desde que respeitados os requisitos limitativos: a patrimonialidade, a disponibilidade, a autonomia das partes envolvidas, 
assim como seja lastreadas pela legalidade estrita (por lei complementar) autorizativa de sua concessão;

g) E, por fim, necessário se faz reformular a gestão administrativa da Fazenda Pública, com a implementação de medidas de cunho técnico-administrativas,como àmelhoria na classificação dos créditos a executar, assim como maior participação dos agentes executivos junto aos agentes do processo judicial, atuando conjuntamente, proporcionando a revisão dos processos que se apresentam como "créditos infrutíferos";

\section{REFERÊNCIAS BIBLIOGRÁFICAS}

ALVES, José Carlos. O protesto de títulos de Dívida Pública. IN: AHUALLI, Tânia Mara; BENACCHIO, Marcelo (coord). Direito Notarial e Registral: homenagem às varas de registros públicos da Comarca de São Paulo. São Paulo: QuartierLatin, 2016.

- O protesto de títulos e documentos de dívida: problemas e perspectivas. IN: Direito Notarial e Registral Avançado. São Paulo: Revista dos Tribunais, 2014.

BECHO, Renato Lopes. Desjudicialização da execução fiscal só mudará o tipo de processo. Disponível em: http://www.conjur.com.br/2014-nov-09/renato-becho-desjudicializacaoexecucao-fiscal-muda-acao. Acesso em: 10/05/2017.

BRAGA, Rafael. Protestos extrajudiciais garantem a recuperação e créditos do INMETRO no Rio Grande do Sul. Disponível em: http://agu.jusbrasil.com.br/noticias/1674147/protestosextrajudiciais-garantem-recuperacao-de creditos-do-inmetro-no-rio-grande-do-sul. Acesso em: 10/05/2017.

CAMPOS, Gustavo Caldas Guimarães de. Execução fiscal e efetividade: análise do modelo brasileiro à luz do sistema português. São Paulo: QuartierLatin, 2009.

CUNHA, Leonardo Carneiro da.A Fazenda Pública em Juízo. 13. ed. Rio de Janeiro: Forense, 2016.

ESCOBAR, Marcelo Ricardo. A arbitragem tributária no direito brasileiro. São Paulo: Almedina, 2017.

GRILLO, Fábio Artigas. Transação e a justiça tributária. 2012, 321 folhas. Tese de doutorado junto ao Programa de Pós-graduação em Direito da Universidade Federal do Paraná. Curitiba, 20 de agosto de 2012.

GRUPO DE ESTUDOS EM ARBITRAGEM TRIBUTÁRIA DO CBAR. Arbitragem tributária é um caminho a ser seguido. Revista Consultor Jurídico. Disponível em: www.conjur.com.br/2017jul-11/opiniao-arbitragem-tributaria-caminho-explorado. Acesso em: 03 de agosto de 2017.

HAIDAR, Fátima Pacheco. Portaria PGFN 396 aprimora a cobrança de créditos tributários. Disponível em: http//www.conjur.com.br/2016-ago-30/fatima-haidar-portaria-pgfn-396aprimora-cobranca-creditos.

Acesso

em:

27/07/2017. 
INSTITUTO DE PESQUISA ECONÔMICA APLICADA (IPEA). Comunicado do IPEA nº 127. Disponível em: http://www.ipea.gov.br/portal/index.php?opition=com_content\&view=article\&id=12794. Acesso em: 01/05/2017.

JORNAL ESTADO DE SÃO PAULO. Refis trazem perda de 18,6 bilhões por ano para a União, diz receita. Disponível em: http://istoe.com.br/refis-trazem-perda-de-r-18,6-bilhoes-por-ano-dizreceita. Acesso em: 10/05/2017.

MACHADO, Hugo de Brito. A transação e arbitragem em matéria tributária. IN: SARAIVA Filho, Oswaldo Othon de; GUIMARÃES, Vasco Branco (org.). Transação e arbitragem no âmbito tributário. São Paulo: Ed. Fórum, 2008.

MORAES, Emanoel Macabu. Protesto notarial: títulos de crédito e documentos de dívida. 3.ed. São Paulo: Saraiva, 2014.

NABAIS, José Casalta. Reflexão sobre a introdução da arbitragem tributária. Revista da Procuradoria Geral da Fazenda Nacional. Brasília, ano I, n. 1, 2009, p. 19-43.

NALINI, José Renato. Execução não é solução! Disponível em: http://reantonalini.wordpress.com/2012/03/18/execucao-nao-e-a-solucao/ Acesso em: 04/05/2017.

PAULSEN, Leandro; ÁVILA, René Bergmann; SLIWKA, Ingrid Schroder. Direito Processual Tributário: processo administrativo fiscal e execução fiscal à luz da doutrina e da jurisprudência. 3.ed. Porto Alegre: Livraria do Advogado, 2007.

TORRES, Heleno Taveira. Princípio da segurança jurídica e transação em matéria tributária: os limites da revisão administrativa a acordos tributários. IN: SARAIVA Filho, Oswaldo Othon de; GUIMARÃES, Vasco Branco (org.). Transação e arbitragem no âmbito tributário. São Paulo: Ed. Fórum, 2008.

TORRES, Ricardo Lobo. Curso de Direito Financeiro e Tributário. 12.ed. Rio de Janeiro: Renovar, 2005.

SANTOS, Reinaldo Velloso dos. Apontamentos sobre o protesto notarial. Dissertação (mestrado em direito comercial), 2012. São Paulo: Faculdade de Direito da Universidade de São Paulo, 2012. Disponível em: http://www.teses.usp.br/teses/disponíveis/2/2132/tde-20032013-142914/. Acesso em: 28/04/2017.

SCHERER, Tiago. Execução Fiscal: novas perspectivas. Revista de Doutrina da $4^{\mathrm{a}}$ Região. Porto Alegre: EMAGIS, n. 64, fev. 2015. Disponível em: http://www.revistadoutrina.trf4.js.br/artigos/edicao064/tiago_scherer.html Acesso em: 02/05/2017. 